\title{
Investigation of Chinese Students Majoring in Occupational and Physical Therapy on Attitude of Evidence-Based Practice
}

\author{
GREINER Bobbi ${ }^{1}$, MU Keli ${ }^{1 *}$, PATTERSON Angela ${ }^{1}$, SCHUMACHER Margaret ${ }^{1}$, QI Yonyue ${ }^{1}$, \\ HU Huiling ${ }^{1}$, XIAO Yue ${ }^{2}$, YANG Yonghong ${ }^{3}$, MENG Fanyuan ${ }^{4}$, LIU Xiaodang ${ }^{5}$, QUI Ya ${ }^{6}$ \\ ${ }^{1}$ School of Pharmacy and Health Professions of Creighton University, Omaha, Nebraska 68178, USA; \\ ${ }^{2}$ Nanjing Medical University, Nanjing, Jiangsu 210029, China; \\ ${ }^{3}$ West China School of Medicine, Sichuan University, Chengdu, Sichuan 610041, China; \\ ${ }^{4}$ Kunming Medical University, Kunming, Yunnan 650500, China; \\ ${ }^{5}$ Shanghai University of Traditional Chinese Medicine, Shanghai 201203, China; \\ ${ }^{6}$ Fujian University of Traditional Chinese Medicine, Fuzhou, Fujian 350122, China \\ *Correspondence: MU Keli, E-mail: kmu@creighton.edu
}

Received 2020-03-07; accepted 2020-05-22

DOI: $10.3724 /$ SP.J.1329.2020.05011

开放科学(资源服务) 标识码 (OSID):

\begin{abstract}
Objective: To examine the attitudes of students majoring in occupational therapy (OT) and physical therapy (PT) on evidence-based practice (EBP) and the possible impact of professional education in China. Methods: A cross-sectional survey of the Evidence-Based Practice Process Assessment Scale (EBPPAS) was administered to OT and PT students from four universities in China. Results: The total mean score of the students' attitudes toward all EBP subscales which included familiarity, attitude, intention, and engagement was 3.18 on a 5-point Likert scale. Significant differences in overall attitude were found between $2^{\text {nd }} \& 3^{\text {rd }}$ year students and $1^{\text {st }}$ year and $4^{\text {th }}$ year students indicating professional education may have impact on students' attitudes $(P=0.031$ and $P<0.001$ respectively). No significant differences were found on the students' perceptions of EBP between OT and PT programs. Conclusion: Chinese OT and PT students both had positive attitudes toward EBP generally. Students' perceptions of EBP tended to improve throughout professional education which suggested the importance of EBP in the professional education of OT and PT.
\end{abstract}

KEY WORDS evidence-based practice; attitude; professional education; occupational therapy; physical therapy

\section{Introduction}

Evidence-based practice (EBP) is essential to provide effective treatment interventions and requires clinicians to learn, seek out, apply, and integrate EBP protocols into clinical practice ${ }^{[1]}$. The emphasis on the use of EBP in clinical practice is increasing globally but is not always routine in occupational and physical therapy practice due to the lack of knowledge, skills or support needed for implementation ${ }^{[2-5]}$. The literature has demonstrated professional education on EBP increases knowledge and skills, impacts attitudes and motivation for health care professionals to engage in EBP ${ }^{[6]}$. As a close link to human being's future be haviors ${ }^{[7]}$, it is imperative to understand professional students' attitudes towards EBP and the possible impact of professional education on their attitudes. Research literature on occupational therapy and physical therapy students' attitudes toward EBP is still scarce, particularly students in the international community. The purpose of this study was to examine the occupational therapy and physical therapy students' attitudes towards EBP in China and to explore whether professional education has impact on the students' attitudes.

\subsection{Health professional student attitudes}

Students in health professions including dentistry, medicine, nursing, chiropractic, social work, OT, PT, and speech and language pathology in the western countries, generally have positive attitudes toward EBP ${ }^{[4,820]}$. However, challenges related to implemen-

\footnotetext{
引用格式:GREINER Bobbi,MU Keli,PATTERSON Angela, 等. 对中国作业治疗和物理治疗专业学生循证实践态度的调查 $[\mathrm{J}]$. 康复学报,2020,30(5):405-412. GREINER B, MU K L, PATTERSON A, et al. Investigation of Chinese students majoring in occupational and physical therapy on attitude of evidence-based practice [J]. Rehabilitation Medicine, 2020,30(5):405-412.
} DOI: $10.3724 /$ SP.J.1329.2020.05011 
tation of EBP in clinical practice were reported across health care professions. Dental students have positive attitudes towards EBP but identify a lack of confidence in appraisal skills, insufficient resources, and

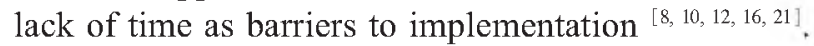
Medical students reported positive attitudes toward EBP but cited lack of adequate training, research space, and mentorship as limitations ${ }^{[20]}$. Similarly, nursing students reported the value of EBP to the profession ${ }^{[22-23]}$. but cited lack of skills and time as barriers to implementation ${ }^{[24]}$. Chiropractic students reported improved attitudes and skills toward EBP after completion of an online course, but this did not translate into increased use in clinical practice ${ }^{[25]}$. Social work students also reported positive attitudes towards EBP and reported familiarity as a significant predictor for intention to use EBP in clinical practice ${ }^{[26]}$. Nonetheless, social work students reported challenges integrating research findings into clinical practice ${ }^{[26]}$.

\subsection{Occupational therapy and physical therapy student attitudes toward EBP}

OT and PT students also demonstrated positive attitudes towards EBP ${ }^{[4,14,18,27]}$. Barriers to EBP implementation included lack of time, insufficient resources, lack of skills to appraise and generalize evidence, and lack of communication skills ${ }^{[14,18,28-29]}$. For PT students specifically, exposure to EBP through coursework demonstrated positive effects on students' attitudes towards EBP ${ }^{[30]}$. More specifically, timing of EPB courses in the curriculum affected students' attitudes and implementation ${ }^{[31]}$. PT students who participated in one EBP course reported decreased feasibility and realistic utility of EBP implementation presumably due to increased awareness of complexity and challenges associated with EBP ${ }^{[30]}$. However, PT students who were enrolled in EBP courses throughout a 4-year education reported significant increases in relevance, confidence, actual knowledge, and practice ${ }^{[31]}$. Post-graduate coursework focusing on EBP improved confidence and decreased anxiety about EBP concepts for PT students in Australia ${ }^{[32]}$. Additionally, a positive association between exposure to EBP and PT students' active EBP behavior during clinical placement, such as the ability to search for and critically appraise EBP, was found for PT students enrolled at a university in Norway ${ }^{[33]}$. Barriers for EBP implementation include lack of time, fear of challenging authority, lack of accessibility and reliability of research, lack of critical appraisal skills, lack of knowledge of scientific methods, as well as lack of communication skills ${ }^{[14,29-30,33]}$. Due to the numerous barriers identified, PT students in the Netherlands reported generally using textbooks and the opinions of supervisors to answer clinical questions ${ }^{[4]}$.

OT students in Ireland reported having a clear understanding and positive attitude towards EBP with intentions to use it in clinical practice, but identified lack of time, fieldwork educators not participating in EBP, and difficulty finding evidence as barriers ${ }^{[17]}$. The participants of the study reported using the internet and textbooks most often to find answers to clinical questions ${ }^{[17]}$. One study reported that OT students had mixed feelings about the value of EBP, identified several barriers to implementation and described the role of EBP curriculum as both vital and imperfect ${ }^{[18]}$. OT students in one study demonstrated increased EBP knowledge and skills pre- and post-course involving EBP content, however, EBP knowledge and skills declined between post-course and post-fieldwork ${ }^{[34]}$. Generally, OT students have positive attitudes towards EBP but are lacking the skills and knowledge to apply it in clinical settings.

Despite being two distinct professions, many similarities have been found between the attitudes of OT and PT students towards EBP. Both OT and PT students place higher value and importance on EBP when they perceive higher expectations of EBP from teachers ${ }^{[15]}$. This finding emphasizes the importance of integrating EBP into OT and PT professional education. OT and PT students have the ability to advance rehabilitative professions through EBP, however, further research is required on the many existing educational and clinical barriers.

\subsection{Impact of professional education}

Knowledge and skills related to EBP are positively impacted by professional education ${ }^{[15,25,29,31-34]}$, and a lack of time spent on EBP correlates with less positive attitudes and skills below competency levels ${ }^{[35]}$. Less is known about how to facilitate the shift from knowledge, skills and attitudes to engagement in clinical practice. A study by Olsen et al. ${ }^{[27]}$ sought to examine the disconnect between attitude, knowledge, skills and engagement of PT students in EBP. The study found that PT students initiated engagement in EBP by searching for evidence to support practice, but they were more eager to learn basic clinical skills not included in those publications ${ }^{[27]}$. This attitude was often supported by clinical instructors that created an environment that did not support the practice of applying EBP knowledge and skills gained in the didactic curriculum ${ }^{[27]}$. Other studies noted weak positive attitude toward EBP among instructors who serve as a role model to students which may have implications on actual engagement in clinical practice as professionals ${ }^{[4,27,29]}$. 
The teaching method and timing of EBP in professional curricula may have an impact on the shift from intention to behaviors. Some suggestions include teaching EBP concepts throughout professional curricula ${ }^{[28]}$, faculty encouragement of students engagement in scholarly activity ${ }^{[20]}$, adding practice opportunities and assignments to apply EBP ${ }^{[36]}$, and increasing discussion between students and clinicians on how to apply EBP in clinical practice ${ }^{[20,36]}$. Differences in knowledge, skills, and attitudes between health professional students should be further explored to develop good practices in EBP instruction.

\subsection{Physical therapy and occupational therapy professionals' attitudes toward EBP}

In order to fully understand the impact of attitudes towards EBP, it is important to consider the attitudes and behaviors of active practitioners. Physical therapists, including practitioners, supervisors of practitioners, and faculty in PT programs, tend to have a positive attitude towards EBP ${ }^{[4]}$. However, practitioners and supervisors of practitioners reported significantly lower perceived behavioral control of research participation than faculty. This may be explained by facility support and increased knowledge of the research process ${ }^{[4]}$. Scholten-Peeters et al. ${ }^{[4]}$ also described practitioners and supervisors as having significantly less confidence and lack of EBP knowledge than faculty. Physical therapists in Kuwait tend to base clinical decisions on knowledge gained from their education and not current research ${ }^{[2]}$. In Saudi Arabia, physical therapists held a positive attitude towards EBP but lacked knowledge on how to implement EBP into clinical practice due to lack of formal education on EBP implementation ${ }^{[37]}$.

\section{Rehabilitation education in China}

Entry level OT, PT, and rehabilitation therapy education in China is a 4-year degree ${ }^{[38]}$. There are multiple Chinese universities that house OT and PT bachelor's degree programs. Currently, six universities in China received certification with the World Federation of Occupational Therapist (WFOT) ${ }^{[39]}$ and five with the World Confederation for Physical Therapy (WCPT) ${ }^{[40]}$. In order to maintain certification with WFOT and WCPT, universities must meet the requirement of teaching EBP within the curriculum as required in the Minimum Standards for the Education of Occupational Therapists ${ }^{[41]}$ and the WCPT Guideline for Physical Therapist Professional Entry Level Education ${ }^{[42]}$. How and when EBP is taught is up to the discretion of the universities. EBP is taught in multiple courses or it is concentrated into an EBP course or a research focused course. Typical OT and PT degrees in China include three years of didactic coursework followed by one year of clinical education providing opportunity for students to translate EBP coursework into clinical practice ${ }^{[3]}$.

\section{Methods}

\subsection{Participants}

A cross-sectional survey was implemented in this study. The questionnaire, Evidence-Based Practice Process Assessment Scale (EBPPAS), developed by Rubin and Parrish ${ }^{[43]}$ was used to investigate the EBP perceptions of OT and PT students in China. The participating OT and PT students were from four universities whose OT and PT programs are certified by the WFOT and WCPT in China. At the time of the study, there were five universities in China whose OT and PT programs were certified by WFOT and WCPT. All five universities were invited to participate in the study and four universities responded to the invitation. All OT and PT students in the four universities were invited to participate in the survey. The study surveyed four classes OT and PT students (i.e. first, second, third, and fourth year students) at each university. Table 1 illustrates the demographics of the participants.

\subsection{Instrument}

The survey utilized in the study was the EvidenceBased Practice Process Assessment Scale (EBPPAS) developed by Rubin and Parrish ${ }^{[43]}$ who documented the EBPPAS' validity, reliability, sensitivity and internal consistency. The original instrument was in English and translation of the questionnaire was made through a structured method to ensure accuracy and reliability. The translation process included forward (English-Chinese) and backward (Chinese-English) translation by two occupational therapy faculty members who are fluent in both Chinese and English in a doctoral occupational therapy program in USA. The Chinese version instrument was then reviewed, and pilot tested for cognitive equivalence by four Chinese OT and PT students who study in USA. Revisions were made to the translated Chinese version based on students' feedback.

The participants completed all 5 sections of the survey: I ) familiarity with $E B P$, II ) attitudes about EBP, III) feasibility of engagement in EBP, IV) intentions to engage in EBP, and V) frequency of engagement in EBP. Additionally, participants completed a demographic section including gender, education program, and year in school. Prior to the completion of section III, IV, and V (sections III, IV, and V pertain to usage of EBP in the clinic), participants were provided a dis- 
claimer to answer the questions based on clinical experiences as a student.

\subsection{Procedure}

Prior to implementation, the study was submitted and approved by the researchers' University Institutional Review Board (IRB number 963329-2). Researchers created an electronic version of the questionnaire in English using Qualtrics software. Researchers contacted one person at each Chinese university who then distributed the survey to the students. The students were briefed on the purpose of the questionnaire, the voluntary nature of participation, and the potential uses of the data being gathered. Students were informed that choosing not to participate would not have any effect on their academic performance or standing with the university. Access to the survey was then provided to the students via email. This email also included instructions for completion of the questionnaire, disclosure of IRB approval, and explicit discussion of the voluntary nature of participation. Two reminder emails were sent to the university representative who then reminded the students to complete the survey.

\subsection{Data management}

Data was collected individually for each OT and PT class from each participating university. These data sets remained separately for the data analysis. Data reports were downloaded using the Qualtrics software and was stored electronically in a password protected location. The data from the completed surveys remained anonymous by assigning identification numbers to each subject and demographic information was not linked to the responses in any way.

\subsection{Data analysis}

Data collected was analyzed via Statistical Package for Social Science (SPSS) for Windows version 25. Descriptive statistics was used to describe student's characteristics and summarize mean scores and standard deviation $(S D)$ for each of the five EBP subscales. One-way ANOVA was used to compare mean scores among four years in program. Independent samples $t$-test was also conducted to investigate if student's responses differed between genders and between OT and PT programs. A $P$-value less than 0.05 was considered statistically significant. $P$-values for post hoc pair comparisons were adjusted by Bonferroni method.

\section{Results}

All OT and PT students from the four participating universities, a total of 1,017 students were invited to participate in the study. Student's characteristics are summarized in Table 1. Six hundred and sixty-four OT, PT, or rehabilitation students from four universities in China completed all or parts of the survey $(65.2 \%$ response rate) despite all the follow up efforts. Rehabilitation students were excluded from analysis due to low number of respondents. Over three-fourths of the students $(76.7 \%)$ were females and nearly 8 out of 10 students $(79.1 \%)$ were PT students. Less than $7 \%$ of the students were freshmen $(n=46)$ and the number of sophomores $(n=211,31.8 \%)$, juniors $(n=194,29.2 \%)$ and seniors $(n=213,32.1 \%)$ were comparable. Ages ranged from 17 to 25 with the mean of 20.58 years $(S D=1.29)$. Mean scores for each EBP subscale was calculated and is represented in Table 2. Results of One-way ANOVA comparing mean scores from four groups based on year in the program $\left(1^{\text {st }}\right.$ year, $2^{\text {nd }}, 3^{\text {rd }}$ year, and $4^{\text {th }}$ year) are represented in Figure 1. Results of $t$-test revealed significant differences between genders and between OT and PT programs, which are represented in Table 3.

\subsection{Overall perception of EBP}

Table 1 Students' demographics ( $n=664)$

\begin{tabular}{lrrcr}
\hline \multirow{2}{*}{ Group } & \multicolumn{4}{c}{ Program } \\
\cline { 2 - 5 } & OT & PT & Rehabilitation & Total \\
\hline $1^{\text {st }}$ year & 2 & 14 & 0 & 16 \\
Male & 4 & 25 & 1 & 30 \\
Female & 6 & 39 & 1 & 46 \\
$1^{\text {st }}$ year total & & & & \\
$2^{\text {nd }}$ year & 2 & 49 & 0 & 51 \\
Male & 31 & 124 & 5 & 160 \\
Female & 33 & 173 & 5 & 211 \\
$2^{\text {nd }}$ year total & & & & \\
$3^{\text {td }}$ year & 1 & 35 & 1 & 37 \\
Male & 25 & 125 & 7 & 157 \\
Female & 26 & 160 & 8 & 194 \\
$3^{\text {td }}$ year total & & & & \\
$4^{\text {th }}$ year & 7 & 43 & 1 & 51 \\
$\quad$ Male & 47 & 110 & 5 & 162 \\
$\quad$ Female & 54 & 153 & 6 & 213 \\
$4^{\text {th }}$ year total & 119 & 525 & 20 & 664 \\
$\quad$ Total & 113 & \\
\hline
\end{tabular}

Table 2 Summary of mean scores for each of EBP subscales

\begin{tabular}{lcccc}
\hline \multicolumn{1}{c}{ Subscale } & $n$ & Mean & $S D$ & $95 \% C I$ \\
\hline Familiarity & 650 & 3.20 & 0.75 & $3.15-3.26$ \\
Attitude & 633 & 3.35 & 0.41 & $3.31-3.38$ \\
Feasibility & 646 & 3.09 & 0.34 & $3.06-3.12$ \\
Intention & 646 & 3.18 & 0.47 & $3.15-3.22$ \\
Engagement & 640 & 3.05 & 0.52 & $3.00-3.09$ \\
Overall & 582 & 3.18 & 0.34 & $3.15-3.20$ \\
\hline
\end{tabular}




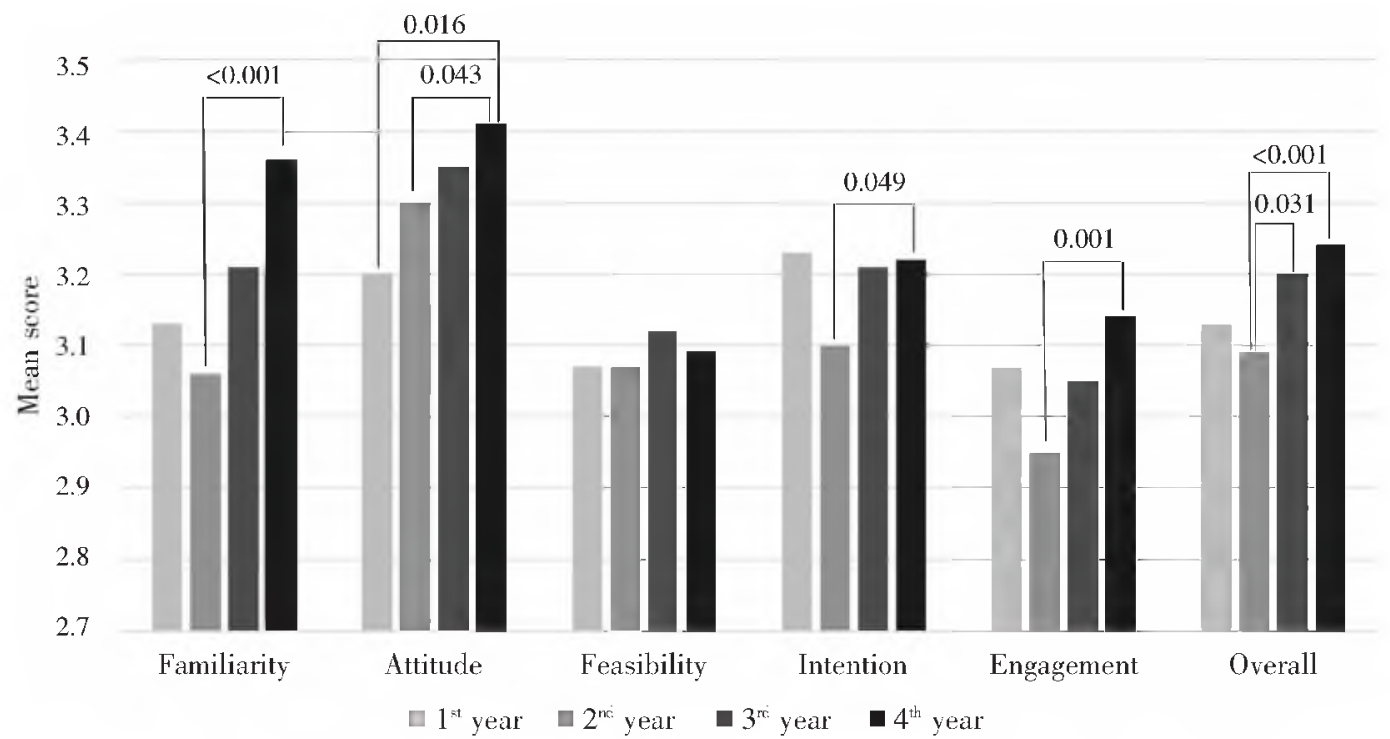

Figure 1 Comparison of mean scores among $1^{\text {st }}, 2^{\text {nd }}, 3^{\text {rd }}$ and $4^{\text {th }}$ year students for overall and each subscale of EBP with One-way ANOVA

Table 3 T-test comparing mean scores between sex, program and years in program for each subscale $(\bar{x} \pm s)$

\begin{tabular}{|c|c|c|c|c|c|c|}
\hline \multirow{2}{*}{ Subscale } & \multicolumn{3}{|c|}{ Gender } & \multicolumn{3}{|c|}{ Program } \\
\hline & Male & Female & $P$ & OT & PT & $P$ \\
\hline Familiarity & $3.37 \pm 0.84$ & $3.15 \pm 0.71$ & 0.004 & $3.17 \pm 0.73$ & $3.22 \pm 0.75$ & 0.498 \\
\hline Attitude & $3.24 \pm 0.41$ & $3.38 \pm 0.40$ & $<0.001$ & $3.51 \pm 0.39$ & $3.31 \pm 0.39$ & $<0.001$ \\
\hline Feasibility & $3.12 \pm 0.34$ & $3.08 \pm 0.34$ & 0.268 & $3.03 \pm 0.31$ & $3.10 \pm 0.35$ & 0.058 \\
\hline Intention & $3.24 \pm 0.50$ & $3.17 \pm 0.46$ & 0.110 & $3.20 \pm 0.47$ & $3.17 \pm 0.47$ & 0.552 \\
\hline Engagement & $3.15 \pm 0.57$ & $3.02 \pm 0.50$ & 0.006 & $3.01 \pm 0.51$ & $3.05 \pm 0.53$ & 0.423 \\
\hline Overall & $3.24 \pm 0.39$ & $3.16 \pm 0.33$ & 0.002 & $3.19 \pm 0.33$ & $3.17 \pm 0.35$ & 0.577 \\
\hline
\end{tabular}

Overall, students generally had a positive attitude toward all EBP subscales with a total mean score of 3.18 of the maximum score of 5 and a standard deviation of 0.34 . Among five subscales of EBP, attitudes toward EBP process had the highest mean score $(3.35 \pm 0.41, S D=0.41)$, while the frequency of current engagement in the EBP process returned the lowest mean score $(3.05 \pm 0.52, S D=0.52)$.

\subsection{Perceptions of EBP among different years of the program}

To examine whether professional education has impact on students' attitudes, participating students' responses from the $1^{\text {st }}$ year, $2^{\text {nd }}$ year, $3^{\text {rd }}$ year and $4^{\text {th }}$ year class were compared. Significant improvement on overall attitudes toward EBP was found from $2^{\text {nd }}$ to $3^{\text {rd }}$ year $(P=0.031)$ and from $2^{\text {nd }}$ year to $4^{\text {th }}$ year students $(P<0.001)$, but not between $1^{\text {st }}$ year and $2^{\text {nd }}$ year students. The $4^{\text {th }}$ year students showed more familiarity with EBP than $2^{\text {nd }}$ year students $(P<0.001)$. The $4^{\text {th }}$ year students also showed more positive attitudes toward EBP whose score is significantly higher than $1^{\text {st }}$ year students $(P=0.016)$ and $2^{\text {nd }}$ year students $(P<0.043)$. In addition, $4^{\text {th }}$ year showed higher intention to engage EBP than $2^{\text {nd }}$ year students $(P=0.049)$ and engaged in
EBP process more often than $2^{\text {nd }}$ year students $(P=0.001)$.

4.3 Perceptions of EBP between different gender and between different program

Overall, there was a significant difference between males and females in their perceptions of EBP ( $P=$ 0.002). Male students showed more familiarity on EBP than female students $(P=0.004)$. Also, male students were more actively engaged in EBP process $(P=0.006)$. Meanwhile, female students had more positive attitudes toward EBP in general than male students $(P<$ $0.001)$. No significant differences were found on students' perceptions of EBP between OT and PT programs ( $P=0.577)$, Ilowever, OT students demonstrated significantly more positive attitudes toward EBP process than PT students $(P<0.001)$.

\section{Discussion}

In general, OT and PT students that participated in this study demonstrated positive attitudes toward EBP, which is similar to previous studies that examined other healthcare professionals' attitudes ${ }^{[4,8-20]}$. Differences in attitudes towards EBP are related to the year in the program, gender and profession along with implica- 
tions that will be discussed below.

\subsection{Differences between program years}

Significant differences are noted between students depending on what year of their program they were studying, which could be explained by when EBP courses are introduced into the curriculum. Study participants were recruited from four Chinese universities that maintained certification with WFOT and WCPT ${ }^{[3940]}$. The first university has courses titled "Evidence- based Practice for Occupational Therapy" and "Evidence-based Practice for Physical Therapy" in the second year of OT and PT education. Students from this university also receive EBP education across professional courses to "improve the professional concept and attitude of the students". The second university incorporates EBP across several courses which start in the second year. The third university teaches a research course in the second semester of the OT curriculum and fourth semester of the PT curriculum. The fourth university introduced either OT or PT into the curriculum in the second year of the bachelor programs resulting in EBP being introduced after that point. The lack of first year student participation may be due to EBP is generally not being taught until the second year of OT and PT education programs. The fourth year in all four Universities is dedicated to clinical practice ${ }^{[43]}$. At this point, all students may begin determining their attitudes towards EBP as it relates to clinical practice and may observe their mentors or clinicians engaged in EBP.

The study findings are consistent with previous research that indicate the positive impact professional education has on attitudes toward EBP ${ }^{[15,25,29,31-34]}$. To be specific, timing and placement of EBP courses have influences on the engagement in EBP in clinical practice ${ }^{[28]}$, which can increase the interaction with clinical faculty and implementation of EBP practice ${ }^{[20,36]}$. The positive impact of professional education on attitudes toward EBP should be interpreted with caution given the fact that EBP related courses are offered in different points of years in program at different universities, the effect of year on EBP attitudes may have been "averaged out".

\subsection{Differences in gender and professional pro- grams}

The ratio of females to males (3:1) may have an impact on general attitude towards the rehabilitation professions and related curriculum. Males reported increased familiarity and current engagement in EBP compared to females. Females reported more positive attitudes toward EBP. It is unclear why there are significant differences between genders in familiarity, attitude, and current engagement in EBP.

Differences in perceptions of EBP between OT and
PT students were minimal, with attitudes towards EBP being the only significance difference (subscale II). Lack of significant differences in attitudes related to familiarity, feasibility, intention to engage, and current engagement suggest that the EBP curriculum and application opportunities for OT and PT students are similar.

\subsection{Intention to engage and current engagement in EBP}

Although this study did not reveal a significant change in feasibility to engage in EBP from $1^{\text {st }}$ to $4^{\text {th }}$ years in the program, there was a significant increase in current engagement in EBP in the $4^{\text {th }}$ year. This may indicate an increased engagement in EBP amongst practitioners in the future, since attitudes can drive future behavior ${ }^{[7]}$.

One third of students who reported that they often engage in EBP were also more likely to read researchbased practice guidelines. This finding is promising in that students may continue this behavior as practitioners rather than relying on knowledge gained from their education alone which will eventually become outdated, a barrier noted in a previous study by Al-Enezi \& May ${ }^{[2]}$. Longitudinal follow-up after years of clinical practice would shed light on the effectiveness of their educational training on long term engagement of EBP.

\subsection{Limitation of the study and conclusion}

The EBPPAS was originally written in English language. The translation into Chinese may be a limitation to the study since there might be subtle differences between the English version and Chinese version of the questionnaire, although efforts were made to eliminate or minimize the possible discrepancy. Also, the validity and reliability of the Chinese questionnaire were not studied. Results of the study could relate to cultural perspective on the use of EBP. Caution should be taken when interpreting the findings of the study. Further research is required comparing data from multiple international OT and PT education programs to determine if EBP attitudes differ between different cultures and level of degree programs (bachelor versus master versus clinical doctorate) is required. This study was also limited to WFOT and WCPT certified universities. Generalization of the study findings to other OT and PT programs especially those without WFOT and WCPT certification is limited.

In conclusion, the overall attitude toward EBP among OT and PT students in China in this study were positive. The study results suggest that the professional education in these four Chinese universities is effective at increasing attitudes towards and engagement in EBP. Approximately one third of participants indicate that they look to the evidence to guide clinical practice decisions suggesting that these students will continue 
to engage in EBP in their future clinical practice. Findings in this study may also suggest that the curriculum in these universities were effective at helping students transfer knowledge and skills to actual engagement at least in the $4^{\text {th }}$ clinical practice year. Since the clinical practice year in professional education is similar to that of first years as a practitioner, it may be possible to conclude that this study may have positive implications related to what the participants' attitudes will be in future years as therapists. More research is needed to focus on the long-term impact on practice behaviors and to determine how professional education can be enhanced to increase the likelihood that more students will transfer their attitudes related to EBP to implementation as future practitioners.

\section{References}

[1] SACKETT D L, ROSENBERG W M. The need for evidencebased medicine [J]. J R Soc Med, 1995, 88(11): 620-624.

[2] AL-ENEZI L, MAY S. Why do physiotherapists do what they do? A study of Kuwaiti physiotherapists $[\mathbf{J}]$. Physiother Res Int, 2017, 22(1): e1640.

[3] LINDSTROM A C, BERNHARDSSON S. Evidence-based practice in primary care occupational therapy: A cross-sectional survey in Sweden [J]. Occup Ther Int, 2018, 2018:5376764.

[4] SCHOLTEN-PEETERS G G M, BEEKMAN-EVERS M S, VAN BOXEL A C J W, et al. Attitude, knowledge and behaviour towards evidence-based medicine of physical therapists, students, teachers and supervisors in the Netherlands: a survey $[\mathrm{J}]$. J Eval Clin Pract, 2013, 19(4): 598-606.

[5] THOMAS A, LAW M C. Evidence-based practice supports among Canadian occupational therapists $[\mathbf{J}]$. Can J Occup Ther, 2014, 81(2):79-92.

[6] DIZON J M R, GRIMMER-SOMERS K, KUMAR S. Effectiveness of the tailored evidence-based practice training program for Filipino physical therapists: a randomized controlled trial $[\mathbf{J}]$. BMC Medl Educ, 2014, 14: 147.

[7] AJZEN I. Nature and operation of attitudes $[\mathbf{J}]$. Ammu Rev Psychol, 2001, 52: 27-58.

[8] CHANG Z C, ZHU C, TAO D Y, et al. A survey on knowledge, attitude and practice related to evidence-based dentistry among dental students [J]. Shanghai Kou Qiang Yi Xue, 2017, 26(2): 204-208.

[9] HAAS M, LEO M, PETERSON D, LEFEBVRE R, et al. Evaluation of the effects of an evidence-based practice curriculum on knowledge, attitudes, and self-assessed skills and behaviors in chiropractic students [J]. J Manipulative Physiol Ther, 2012, 35(9): 701-709.

[10] HOLMAN S D, WIETECHA M S, GULLARD A, et al. U.S. dental students' attitudes toward research and science: impact of research experience [J]. J Dental Educ, 2014, 78(3): 334-348.

[11] RAMIS M, CHANG A, NISSEN L. Undergraduate health students' intention to use evidence-based practice after graduation: A systematic review of predictive modeling studies $[\mathbf{J}]$. Worldviews Evid Based Nurs, 2018, 15(2): 140-148.

[12] RYAN E J. Undergraduate nursing students' attitudes and use of research and evidence-based practice- an integrative literature review [J]. J Clin Nurs, 2016, 25(11-12): 1548-1556.

[13] SCURLOCK-EVANS L, UPTON P, ROUSE J, et al. To embed or not to embed? A longitudinal study exploring the impact of curriculum design on the evidence-based practice profiles of UK pre-registration nursing students $[\mathbf{J}]$. Nurse Educ Today, 2017, 58: $12-18$

[14] SHAIKH A A, GAD A. Evidence-based practice: Knowledge, at- titude and practice of physiotherapy students in Maharashtra [J]. Indian J Physiother Occup Ther, 2017, 11(2): 53-57.

[15] SNIBSØER A K, GRAVERHOLT B, NORTVEDT M W, et al. Evidence-based practice profiles among bachelor students in four health disciplines: a cross-sectional study $[\mathrm{J}]$. BMC Med Educ, 2018, 18(1): 210 .

[16] STRAUB-MORAREND C, WANKIIRI-HALE C, BLANCHETTE D R, et al. Evidence-based practice knowledge, perceptions, and behavior: A multi-institutional, cross-sectional study of a population of U.S. dental students [J]. J Dent Educ, 2016, 80(4): $430-438$

[17] STRONGE M, CAHILL M. Self-reported knowledge, attitudes and behavior towards evidence-based practice of occupational therapy students in Ireland $[\mathbf{J}]$. Occup Ther Int, 2012, 19(1): $7-16$.

[18] THOMAS A, HAN L, OSLER B, et al. Students' attitudes and perceptions of teaching and assessment of evidence-based practice in an occupational therapy professional Master's curriculum: a mixed methods study [J]. BMC Med Educ, 2017, 17(1): 64.

[19] TOGHER L, YIANNOUKAS C, LINCOLN M, et al. Evidencebased practice in speech-language pathology curricula: a scoping study [J]. Int J Speech Lang Pathol, 2011, 13(6): 459-468.

[20] TURK T, AL SAADI T, ALKHATIB M, et al. Attitudes, barriers, and practices toward research and publication among medical students at the University of Damascus, Syria $[\mathbf{J}]$. Avicenna J Med, 2018, 8(1): 24-33.

[21 ] SANTIAGO V, CARDENAS M, CHARLES A L, et al. Evidencebased practice knowledge, attitude, access and confidence: A comparison of dental hygiene and dental students $[\mathrm{J}]$. J Dent Hyg, 2018, 92(2): 31-37.

[22] BROOKE J, HVALIC-TOUZERY S, SKELA-SAVIC B. Student nurse perceptions on evidence-based practice and research: An exploratory research study involving students from the university of Greenwich, England and the faculty of health care Jesenice, Slovenia [J]. Nurse Educ Today, 2015, 35(7): e6-e11.

[23] KARKI S, ACHARYA R, BUDHWANT H, et al. Perceptions and attitudes towards evidence-based practice among nurses and nursing students in Nepal [J]. Kathmandu Univ Med J, 2015, 13(52): 308-315.

[24] ROJJANASRIRAT W, RICE J. Evidence-based practice knowledge, attitudes, and practice of online graduate nursing students $[\mathrm{J}]$. Nurse Educ Today, 2017, 53: 48-53.

[25] SCHNEIDER M, EVANS R, HAAS M, et al. The effectiveness and feasibility of an online educational program for improving evidence-based practice literacy: An exploratory randomized study of US chiropractors [J]. Chiropr Man Therap, 2016, 24: 27.

[26] IOVU M B. Intentions to engage in evidence-based practice among undergraduate social work students: Preliminary findings from Romania [J]. J Evid Inf Soc Work, 2015, 12(3): 302-309.

[27] OLSEN NR, BRADLEY P, LOMBORG K, et al. Evidence based practice in clinical physiotherapy education: A qualitative interpretive description [J]. BMC Med Educ, 2013, 13: 52.

[28 ] SCHOONEES A, ROHWER A, YOUNG T. Evaluating evidencebased health care teaching and learning in the undergraduate human nutrition, occupational therapy, physiotherapy, and speech, language and hearing therapy programs at a sub-Saharan African academic institution [J]. Plos One, 2017, 12(2): e0172199.

[29] PERRATON L, MACHOTKA Z, GIBBS C, et al. Evidence-based practice intentions and long-term behaviours of physiotherapy graduates following an intensive education programme $[\mathbf{J}]$. Physiother Res Int, 2017, 22(3): el666.

[30] HAYWARD L M, ENGLISH M. What's the task value? Understanding Doctor of Physical Therapy Students' perceptions of the value and relevance of evidence-based practice $[\mathbf{J}]$. J Phys Ther Educ, 2018, 32(3): 300-309.

[31] MCEVOY M P, LEWIS L K, LUKER J. Changes in physiotherapy students' knowledge and perceptions of EBP from first year to graduation: A mixed methods study $[\mathrm{J}]$. BMC Med Educ, 2018, 18(1): 109 . 
[32] PERRATON L, MACHOTKA Z, GRIMMER K, et al. Embedding evidence-based practice education into a post-graduate physiotherapy program: eight years of pre-post course evaluations $[\mathbf{J}]$. Physiother Res Int, 2017, 22(2): e1659

[33] OLSEN N R, LYGREN H, ESPEHAUG B, et al. Evidencebased practice exposure and physiotherapy students' behaviour during clinical placements: a survey $[\mathbf{J}]$. Physiother Res Int, 2014, 19(4): 238-247.

[34] CRABTREE J L, JUSTISS M, SWINEHART S. Occupational therapy master-level students' evidence-based practice knowledge and skills before and after fieldwork $[\mathrm{J}]$. Occup Ther Health Care, 2012, 26(2-3): 138-149

[35] BAHAMMAM M A, LINJAWI A I. Knowledge, attitude, and barriers towards the use of evidence-based practice among senior dental and medical students in Western Saudi Arabia $[\mathbf{J}]$. Saudi Med J, 2014, 35(10): 1250-1256.

[36] KIM S S, KIM E J, LIM J Y, et al. Korean nursing students' acquisition of evidence-based practice and critical thinking skills $[\mathbf{J}]$. J Nurs Educ, 2018, 57(1): 21-27.

[37] ALSHEHRI M A, ALALAWI A, ALHASAN H, et al. Physiotherapists' behaviour, attitudes, awareness, knowledge and barriers in relation to evidence-based practice implementation in Saudi Arabia: a cross-sectional study $[\mathbf{J}]$. Int $\mathbf{J}$ Evid Based Healthc, 2017, 15(3): 127-141.
[38 ] JONES A, SKINNER M A. The current status of physical therapy in China [J]. Chin J Rehabil Med, 2013, 28(6):493-501.

[39] World Federation of Occupational Therapists (WFOT). WFOT approved education programmes [EB/OL]. (2019-03-10) [201903-31 ]. https://www.wfot.org/programmes/education/wfot-approved-education-programmes.

[40 ] World Confederation for Physical Therapy (WCPT). WCPT accredited programmes [EB/OL ]. (2019-03-04) [2019-03-31 ]. https://www.wfot.org/programmes/education/wfot-approved-education-programmes.

[41] World Federation of Occupational Therapists (WFOT). Minimum standards for the education of occupational therapists $[\mathrm{EB} / \mathrm{OL}]$. (2016-02-04) [2019-03-31]. https://wfot.org/assets/resources/ COPYRIGHTED-World-Federation-of-Occupational-TherapistsMinimum-Standards-for-the-Education-of-Occupational- Therapists-2016a.pdf.

[42] World Confederation for Physical Therapy. WCPT guideline for physical therapist professional entry level education $[\mathrm{EB} / \mathrm{OL}]$. (2011-02-04) [2019-03-31]. https://www.wcpt.org/sites/wcpt.org/ files/files/Guideline_PTEducation_complete.pdf.

[43] RUBIN A, PARRISH D E. Development and validation of the evidence-based practice process assessment scale: preliminary findings $[\mathrm{J}]$. Res Soc Work Pract, 2010, 20(6): 629-640.

\section{对中国作业治疗和物理治疗专业学生 循证实践态度的调查}

GREINER Bobbi ${ }^{1}$, MU Keli ${ }^{1 *}$ PATTERSON Angela ${ }^{1}$, SCHUMACHER Margaret ${ }^{1}$, QI Yonyue ${ }^{1}$, HU Huiling ${ }^{1}$, XIAO Yue ${ }^{2}$, YANG Yonghong ${ }^{3}$, MENG Fanyuan ${ }^{4}$, LIU Xiaodang ${ }^{5}$, QUI Ya ${ }^{6}$

1 美国克瑞顿大学药学与健康专业学院, 奥马哈, 内布拉斯加 68178 , 美国;

2 南京医科大学, 江苏南京 210029 ;

3 四川大学华西医学院, 四川成都 610041;

4 昆明医科大学,云南 昆明 650500 ;

5 上海中医药大学, 上海 201203;

6 福建中医药大学, 福建 福州 350122

*通信作者:MU Keli,E-mail:kmu@creighton.edu

摘要 目的: 探讨作业治疗 (OT) 和物理治疗 (PT) 专业的各年级学生对循证实践的态度, 以及专业教育对中 国学生态度的可能影响。方法: 对中国 4 所大学的 OT 和 PT 学生进行循证实践评估量表(EBPPAS)的横断 面调查。结果: 在 5 点李克特量表上, 学生对包括熟悉度、态度、意图和参与度的 EBP 量表态度的平均总得分 为 3.18 分。在二年级、三年级学生之间与一年级、四年级学生之间发现总体态度差异均有统计学意义 $(P=$ 0.031 和 $P<0.001)$, 表明专业教育可能会影响学生的态度。OT 和 PT 专业学生对 EBP 的理解差异无统计学 意义 $(P>0.05)$ 。结论: 中国的 $\mathrm{OT}$ 和 $\mathrm{PT}$ 学生普遍对 $\mathrm{EBP}$ 持积被态度。在整个专业教育中, 学生对循证实践 的认识趋于提高, 这表明循证实践在 $\mathrm{OT}$ 和 PT 专业教育中的重要性。

关键词循证实践; 态度; 专业教育;作业治疗;物理治疗

DOI : $10.3724 /$ SP.J.1329.2020.05011 